\title{
Renaissance's Accelerated Reader: Does It Really Work?
}

S chool libraries have been trying many different ways to encourage students to read. Over the years, programs like Accelerated Reader, by the company Renaissance, have been thought to be the best for keeping students engaged in reading and understanding content. Accelerated Reader has been on the market for over two decades, but there has been very little research showing the success of the program. Research that is present about Accelerated Reader (2019) is exclusively provided by Renaissance. It appears that the data is skewed due to the sole producer of the statistics and reports.

Accelerated Reader has a structure of students checking out books on the reading level range. This range is assigned to the student after taking the STAR Assessment Test. This test evaluates student's comprehension and reading skills to help put students within their reading level range. It is beneficial for teachers to help know what the average reading level the class is on. The students read their books and once they finish, they take a test on the book. The questions are usually about plot points from the book to help ensure the student has read and understood the book. Depending on their score of how they did on the test they are assigned points, which are preassigned to the book. Schools try to incentivize reading to students based on how many points they have accrued over the school year.

Accelerated Reader's What Kids are Reading Report (2019) reports that "Students are reading at levels at the very bottom of the recommended reading ranges for their grades, and at levels that are far below real world materials such as college texts, workforce documents, and popular books and media." (p. 15). The data alone is not specified as to where it comes from. It is assumed that the data comes from Accelerated Reader, as the rest of the data derives from it as well. Their argument throughout the report is that if students were to read at least fifteen minutes a night they would see their reading levels start to progress. While this is a great goal to have for students it is ineffective to base the data solely off of their own data.

Accelerated Reader's statement is "Accelerated Reader is a research-based reading practice program that equips teachers with unparalleled insight into independent reading practice, personalized goal-setting tools, activities that span a variety of skills and text types and a worldwide community of support." (p. 41). The statement shows that it gears its program toward teachers and not the school librarians. While this is important it is the school librarians who have to promote the program, order the quizzes, label the books, and analyze the data. The promotion and rules of the program are not for school librarians to decide. School librarians are not allowed to make decisions based on Accelerated Reader for classrooms, so it causes the teachers to create the rules that end up becoming library rules. The teachers emphasize their regulations that school librarians have to follow. The program excludes the very individuals who are supposed to organize the program within the school. That is problematic for school librarians to feel involved in the program and want to promote it. It is important to allow school librarians to be the advocate for the library and its programs, but once it is denied to the librarian it becomes a messy situation. While Accelerated Reader is beneficial for teacher usage it is not implemented in the right way due to the exclusion of the school librarian.

The Accelerated Reader program is bundled and modified for individual schools based on the size of the student body. According to Mark T. (personal communication, November $20^{\text {th }}$, 2019), a sales representative of Accelerated Reader, the base plan for the program is $\$ 1,450.00$ for the first 100 students. After that it goes by per student of $\$ 7.00$ each. Most elementary schools average about 400 students. The basic package becomes $\$ 3,550.00$. However, schools also need to purchase the STAR Assessment Tests to place students on their reading level. The package is $\$ 500.00$ per 100 students making it $\$ 2,000.00$ based on a population of 400 students. The total amount for a school size of 400 students is $\$ 5,550.00$ for one school year. The training of staff and stickers that are used to label the book are not included in this price. The price is just for the computerized program itself. That is why it is important to evaluate Accelerated Reader to determine if it is even beneficial for the school and its students.

The main issue with the program is how it has been construed to limit student's ability to read what they would like. Some schools have forced students to only check out materials 
that is on their Accelerated Reader (A.R.) level. Forcing students to only check out certain materials is problematic for students, because most schools prevent students to check out the books that they want if the book is above or below their A.R. level. Students can become frustrated with reading when they are presented with so many issues regarding it. The books that they want to read are being restricted from them. While it could be argued that students could get the books they want from public libraries instead of the school library, this can be difficult for students to find access to get to the public library in the first place. Students are reliant on parents taking them to the public library. Lack of transportation to the public library takes away the ease of access that school libraries already possess. It would be much more efficient to let the student check out the book that is already on the shelf in the school library. Allowing students to check out any book even if it is not on their reading level, provides open access for the students of which libraries are supposed to be for. Not every book published is an Accelerated Reader book. If Accelerated Reader did not like a book based on content or bias, they do not have to include it making it unavailable for students to read. Accelerated Reader allowing their biases to determine which books to exclude can lead school libraries to stray away from great books on the basis that it is not useful without the Accelerated Reader quiz.

Accelerated Reader tries to assess a student's reading level and keeping them in their range to help develop their reading skills. Accelerated Reader assessment of assigning students to specific reading levels is not explained thoroughly. The STAR Assessment Test is the reasoning for forcing students to stay on their reading level. It is what the test evaluates them to be at. The structure of the program causes it to censor books from students.

Student privacy and confidentiality is violated by the obvious labeling of book levels stuck on the individual books. If students are forced to check out materials on a certain A.R. level

content, thus creating entire "classes" of books that readers avoid or that parents or teachers deem to be offlimits to certain groups of students." (p. 90). Students can create unhealthy habits of not reading for learning or enjoyment, but to read for point values. Students will pick books based

\section{Students can create unhealthy habits of not reading for learning or enjoyment, but to read for point values.9}

it will take away their privacy of their reading abilities due to other students or teachers knowing what they are able to read and understand. The learning experience is taken away from the student, because they can become selfconscious of their level. Teachers want to know what students are reading to ensure they are on their level. It is unethical to tell someone else, other than the parents, what a student is reading. It is also unethical to tell student's reading skills to anyone but the parent. It goes against the student's confidentiality. These violations are a side effect of Accelerated Reader, not a direct cause of it.

The aspect of students reading for points instead of enjoyment or learning is a direct cause of Accelerated Reader. Points are attributed to the books based on their A.R. level after students take a test on the book. If they do well on the test, they will receive points based on their comprehension of the book. Some schools do parties or award ceremonies if students have gained enough points by the end of the term. It leads some students to read books that are shorter to do more tests, than if they were to read a book of interest that may take longer with fewer points. Hunt (2012) states that "However the same labeling practices can lead readers to prejudge books by their labels rather than by their solely on their point values making it a race to get more points to attend the parties and award ceremonies. Accelerated Reader's ideology makes students read for points to help incentivize reading to eventually create reading for learning and enjoyment. School libraries are the heart of the school. It is important to instill a love of reading, researching, and open access that school libraries provide in order to keep students coming back and to become lifelong readers.

Some may argue that the school's job for students is to protect the students from content is too mature. The argument for Accelerated Reader is that the teachers and parents can assure that students are reading appropriate books based on their age level. Rubin (2016) mentions throughout the chapters about intellectual freedom and censorship of materials for children. He explains that "Parents expect schools to protect their children from harm; indeed, schools are legally obligated to do so." (p. 515). He also brings up patron confidentiality and privacy and explains that it is important to uphold this rights that the patron has. While the school system is legally obligated to protect students from subjects that are too mature, that does not mean that they should prevent students from reading books that are above or below the student's 
A.R. level. Preventing students from reading certain books is not protecting children from harm, this is censorship.

Accelerated Reader's reading level decision making reasons are not explicit. The regulations for why a book is on that level seems to be based more so on the thickness of the book versus the content. Powers (2013) acknowledges that "Nor are reading levels intended to coincide with grade level. The Color Purple by Alice Walker, for example, includes some explicit sexual content and may be considered appropriate only for older readers. The book, however, is identified by AR as a "book level" of 4.0, by Reading Counts as a "grade level" of 7.2 and has a Lexile Level of 670.” (p. 18). Powers argument shows how Accelerated Reader does not account for content and maturity levels of books that schools must uphold. Accelerated Reader does not take this into consideration when making reading levels. It can lead some students to find a book that is on their reading level, but they are unable to comprehend the content. According to Pentland (2019) "It is important to remember that reading levels are to be used to help inform teacher instruction, not to make personal reading selections." (p. 19). Helping teachers was the intended use for reading levels, but schools unfortunately forced it to influence reading selections. It is important for school librarians to advocate for their students right to read. School librarians must advocate for their libraries in order help others understand the ethical issues that are being created by programs such as these. It is the responsibility of the librarian to advocate for their students and the library to ensure that it will remain there for years to come.

Accelerated Reader's creation was more so for teacher usage rather than school librarians, based on
Accelerated Reader's 2019 report. The lack of consideration of library core values is how it violates student's rights. The teachers do not know these values that libraries share, and they need to make sure their students are developing before the annual standardized testing session. Accelerated Reader could have been a great program that enabled struggling readers to become lifelong readers. The program unfortunately causes ethical dilemmas to occur due to the structure of the program. It should be evaluated whether or not schools actually benefit from the program. Through the research found it is not enough to determine that it should be kept in most school systems due to the unethical dilemmas it creates among school libraries and its students.

The long-term effects of Accelerated Reader being implemented in schools can be detrimental to student's reading skills. It forces students to read books on their level not allowing them to read books that are considered to be too difficult. Children who always have their books picked out for them do not develop the skillset of choosing their own books. According to Miller (2009) "Furthermore, shifting the purpose for reading a book toward the memorization of plot details and away from an overall appreciation for the book changes how students read. Instead of falling into a book and traveling on a journey with the characters, readers float on the surface of the story and cherry-pick moments they predict they will be tested on later." . Lacking this skillset does not create lifelong readers, because they don't know what they want to read. The students were never given the opportunity to challenge themselves to find the books that appealed to them. The whole goal of Accelerated Reader is to help create lifelong readers, but it does not satisfy its own goal.
Accelerated Reader prevents students from discovering other books that are considered classics due to it being above or below the students reading level. Books that are not assigned quizzes are also dismissed due to it not being beneficial for the student to read. It is important to remember that authors do not write books based on Accelerated Reader levels. The authors write books based on the age group and interests of the group. It is possible to categorize each book into its own specific level, but it can cause great books to become overlooked due to the leveling. According to Melton et. all (2004) "It should be noted that students who did not participate in the Accelerated Reader program showed a significant increase in reading achievement growth when compared to students who had participated in the Accelerated Reader program for a year.". Based on their study students who did not participate showed more growth than those who were. This shows how when students are able to choose the books they want to read from authors they enjoy they will succeed more.

Public and academic libraries are not structured based on reading levels. It is important for schools to have real world applications throughout to help students when they one day graduate. Students should learn how to navigate a library to be able to find their own books. Students should learn how to comprehend books without having to take quizzes to ensure reading. These practices are not done in real world settings which make it important to integrate it to students so they will be able to gain the knowledge to navigate the world.

The American Association of School Librarians (2011) is firm on their viewpoint that "School Librarians should resist labeling and advocate for development of district policies 
regarding leveled reading programs that rely on library staff compliance with library book labeling and nonstandard shelving requirements." (p. 1). While the association puts an emphasis on labeling books based on reading levels, they mention in the position that right to access of resources should be available without restriction is their main goal. These goals and viewpoints do not align with how Accelerated Reader is being used in school libraries. The program is a clear violation of right to access and confidentiality. The American Association of School Librarians creates the standards for school librarians across the country making it important to align with their viewpoint.

There are many other alternatives to engage and track reading from students versus using Accelerated Reader. Giorgis (2019) suggests that "Before committing precious dollars to such a program, a district should decide its purpose: Is the program there to motivate children to read or to create another grading platform?”. It is important for school librarians to collaborate with teachers to help integrate an environment of reading throughout the school. Promotion of reading can be done with read-a-thons, culture of reading, and reading incentives. Reada-thons are events that allow children to just lounge and read all day. Reada-thons could be a special prize for students who have behaved and done well on assignments to be able to read their books all day. Promoting a culture of reading throughout the school by having time set aside for reading can help students gain practice and skills. It is important that the teacher reads during this time too, because students model after what they see adults doing. To emphasize to the students that reading helps progression in all subjects not just one. Reading promotion can be done by having students read a certain number of minutes a night by recording it on a reading log. Reading logs help keep students on track with reading, but it allows them to read what they want to read. Reading logs are a great way to help students develop discovering what they want to read versus making reading levels choose for them.

Teachers prefer Accelerated Reader because of the ease of knowing makes sure that students read the book from their quizzes. Giorgis (2019) states that "Some teachers and librarians stop reading children's and young adult books because the computer will ask the questions instead.". This makes it easier for the teachers to focus on other things, but it is important to read the books that the students are reading. Tracking student's comprehension can be done by creating an open discussion for the whole class to discuss what books they've read and what it was about. It will allow students to explain what they liked or disliked about the book and what the understood the book to be about. Another option is to have a worksheet that students do at the end of each book that has open ended questions that could be applied to all books so the student can prove they have read the book. Students are given a chance to give their feedback of the book and allow them to form their own opinions of the book.

The amount of money that Accelerated Reader costs can put a dent into a school library's budget. The money could go toward buying more up to date books that are relevant to the student's interests and curriculum. Makerspaces are trending in school libraries to help promote science, technology, engineering, and mathematics (STEM). Makerspaces could be purchased to use during library lessons to help engage students. Purchasing books for the library are what helps students read, not tests that evaluate whether the student has read the book.

One of the jobs a school librarian does is collaborate with teachers. Librarians are specialists in collaborating to help find new lesson plan ideas, resources, or ideas to help make things easier. Teachers could collaborate with school librarians to find a happy medium of how to track reading and progression in a way that does not hinder their reading. According to Nicole Guldager (2016) "The goal is to collaborate with classroom teachers and support instruction across the school, yet many aspects of how programs such as Accelerated Reader and Scholastic Reading Counts are implemented within buildings disrupt the teacher librarian's attempts at encouraging reading autonomy, reading for pleasure, and self-guided inquiry." (p. 18). School librarians have been collaborating with teachers before Accelerated Reader was created. Collaboration within the school is beneficial for everyone, so ideas can be utilized for more efficiency.

Teachers are the biggest motivators for Accelerated Reader, because of how they can keep track of student's progression and reading. There are many ways teachers can implement safer reading motivators without the usage of Accelerated Reader. Through reada-thons, open ended worksheets, discussions, and creating a culture of reading students can gain progression, comprehension, and create a love of reading that Accelerated Reader fails to do.

Accelerated Reader created an opportunity for schools to try a new program to engage students into reading. The ability to track the points that students have to award those who have achieved their reading goal was appealing to schools for the acquisition of Accelerated Reader. While the program's initial idea seems rewarding to students and the school it has created 
ethical issues of censorship and invasion of privacy. Teachers have implemented rules alongside of Accelerated Reader that students must stay on their reading level which can prevent students from checking out materials that they desire to. Censorship prevents students from reading books that are deemed too complicated or too easy for them. The labeling of reading levels on the books also makes it easy for other students to read what other students reading levels are, invading their privacy. School librarians are not involved in the decision making with Accelerated Reader. A better idea is for collaborative work between school librarians and teachers is to promote reading events to engage students to become lifelong learners. Alternatives that could be more beneficial instead of Accelerated Reader are read-a-thons, book discussion, reading logs, and open discussion worksheets. These events will help students choose their own books allowing personal growth. Accelerated Reader is an outdated program that causes ethical dilemmas that could be resolved by school librarian and teacher collaboration to help promote to students a love of reading.

\section{Bibliography}

American Association School Librarians (2011). Position statement on labeling books with reading levels, Retrieved from http://www.ala.org/aasl/advocacy/resources/statements/labeling (Accessed November 19, 2019)

Giorgis, C. (2019) Jim Trelease's read-aloud handbook eighth edition. New York, NY: Penguin Random House.

Guldager, N., Kreuger, K., \& Taylor, J. (2016). Reading promotion events recommended for elementary students.

Teacher Librarian vol. 43. issue 5. Retrieved from http://scholarworks.uni.edu/cgi/viewcontent. cgi?article $=1004 \&$ context $=$ ci_facpub

Hunt, L. (2012). Does labeling children's books constitute censorship?. Reference and User Services Quarterly vol. 52 issue 2.

Melton, C., Smothers, B., Anderson, E., Fulton, R., Replogle, W., and Thomas, L. (2004). Study of the effects of the Accelerated Reader program on fifth grade students' reading achievement growth. Read Improv vol. 41 issue 1.

Miller, D. (2009). The Book whisperer: Awakening the inner reader in every child. San Francisco, CA: A Wiley Imprint.

Pentland, C. (2019). Ensuring equitable access to books in the school library. Teacher Librarian, 46, 18-21. Retrieved from http://nclive.org/cgi-bin/nclsm?url=http://search.proquest.com/docview/2288608118?accountid=13565

Powers, R. (2013). Guide to reading levels. American Libraries, 44, 18-19. Retrieved from http://search.proquest. com.jproxy.lib.ecu.edu/docview/1433471287? accountid=10639

Renaissance Learning. (2019). What kids are reading: World's largest annual study of K-12 reading habits: 2019 edition. Wisconsin Rapids, WI: Renaissance Learning Inc.

Rubin, R. (2016). Foundations of library and information science ( $4^{\text {th }}$ ed). Chicago, IL: American Library Association.

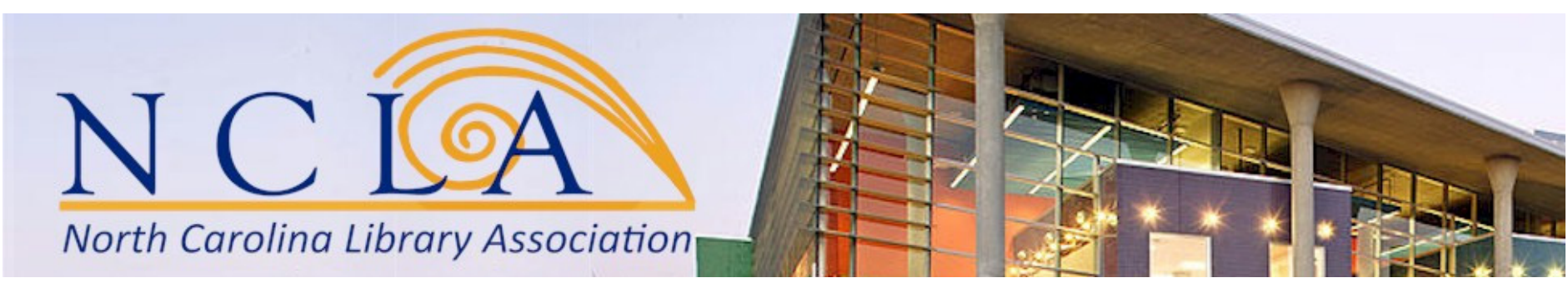

http://www.nclaonline.org/ 